\title{
Beauty constructs for MP3 players
}

\author{
Ali al-Azzawi \\ Digital World Research Centre \\ \& Department of Psychology \\ University of Surrey, Guildford, \\ Surrey GU2 7XH, U.K. \\ a.al-azzawi@surrey.ac.uk
}

\author{
David Frohlich \\ Digital World Research Centre \\ University of Surrey, Guildford, \\ Surrey GU2 7XH, U.K. \\ d.frohlich@surrey.ac.uk
}

\author{
Margaret Wilson \\ Department of Psychology \\ University of Surrey, Guildford, \\ Surrey GU2 7XH, U.K. \\ m.wilson@surrey.ac.uk
}

\begin{abstract}
This paper contributes to the current debate about the nature of beauty and aesthetics as they apply to interactive products. Current disagreement centres around the question of whether beauty should be viewed as a continuous property of objects or as a rare emotional response to object encounters (Hassenzahl 2004, Frohlich 2004). Here we develop a new perspective of beauty as a complex psychological construct, subject to competing influences from visible object properties such as shape and colour, and invisible object associations such as perceived ease of use and brand. We introduce a new methodology for examining such constructs based on a card sorting procedure, and use it to show how 36 participants think about the beauty of $35 \mathrm{MP} 3$ players. One major finding is that participants tended to evaluate the players holistically, applying similar categorisations to free sorts, beauty sorts and preference sorts. This involved a common polarisation between modern and post-modern forms as they have been found to apply to architectural styles (Wilson 1996).
\end{abstract}

\section{INTRODUCTION}

The field of human computer interaction (HCI) was initially established to examine the relationship between people and computers, at a time when getting the computer to do what you wanted was a major challenge (e.g. Card, Moran \& Newell 1983). Considerations of the beauty of a computer did not arise in this era, which was more dominated by considerations of error, incomprehension and frustration. Things are very different today in a context where the interfaces to personal computers have standardised around a handful of operating systems and common applications, and the design of the computer itself has become a differentiator for consumer sales. Computing resources are also assuming a variety of novel forms, as they become embedded in portable physical objects or situated architectural surfaces. This is leading to a merging of human computer interaction with product design and architecture, and a re-framing of questions of aesthetics, pleasure and fun as they apply to interactive experiences (e.g. Blythe et al 2003, Jordan 2000, McCarthy \& Wright 2004, Norman 2004).

One debate to arise out of these developments is about the nature of beauty and how it relates to digital products. A recent set of discussions have been published in the Human Computer Interaction journal, around a new study by Hassenzahl (HCI Special Issue 2004 Volume 19). Hassenzahl (2004) undertook a study to examine the beauty of software MP3 players and its relationship to other attributes such as usability and goodness, using a series of bipolar rating scales and correlations between them. He suggests that perceived beauty is more related to judgements of hedonic identification or self-presentation, than to judgements of usability or other kinds of hedonic stimulation (pleasure). This contradicts previous work which showed that perceptions of beauty affected perceptions of usability, such that 'what is beautiful is usable' (Tractinsky et al 2000).

Irrespective of the particular findings reported, Hassenzahl's paper has sparked a discussion about the nature of beauty in HCI and how to measure it. Hassenzahl's view that beauty is a continuous property of an interactive artefact, whose extent can be measured on a simple rating scale, was challenged by Frohlich (2004). Frohlich observed that beauty has been defined differently in classical philosophy, as a rare all-or-nothing response to an object experienced in a particular context, and may not have been present at all in Hassenzahl's experiment or others' like it. He recommended studying beauty by collecting stories of 
its occurrence, wherever it can be found. Unfortunately this is not a practicable method that can be applied to a specific product's design. It closes off a form of affective engineering to assess the impact of design alternatives on related judgements or experiences of beauty. If beauty really is so rare, how can people compare the beauty of individual items and what are they really thinking about when they do this?

In this paper we address this question and debate by introducing a new methodology for studying beauty as a multi-faceted psychological construct. We argue that different "Kinds of Beauty" may be perceived in relation to different product options based on comparisons between them, and that these perceptions co-exist alongside other constructs, including overall preference. We also examine the relationship between preference and beauty.

There is wide agreement to the notion that in order to arrive at more meaningful theory and understanding, it is important to elicit data in a clean way without researcher influence. We have adopted the Facet Theory approach (Canter 1985, Shye et al 1994), which has had much success in other areas of psychology and aesthetics (Wilson 1994 \& 1996). Wilson's previous work showed insight into the relationship between architecture style and preference. This approach is based upon gathering data without any assumptions regarding individual users' constructs, unlike other methods where the constructs are predefined such as semantic differential scale (Osgood et al 1957).

Our methodology is based on a Multiple Sorting Procedure (MSP), a card sorting procedure originally developed to examine people's conceptual system and to elicit their constructs and categories for a given context (Canter et al 1985). It has been successfully applied to the perception of architectural style in buildings (Wilson \& Canter 1990), and has become a useful tool in environmental psychology. We apply it here for the first time to the perception of interactive products, and show how it begins to reveal how users themselves define and discuss aesthetic properties.

\section{METHOD}

\section{Participants}

Thirty participants volunteered to take part in the study (15 males \& 15 females, average age $=23.9$ years $($ range $=27)$ ). For the preference data, there were 6 extra participants (18 males \& 18 females, average age $=23.9$ years $($ range $=27)$ ). Each participant was given 35 cards (Figure-1) that showed a good quality, colour, life-sized photograph of a hand-held portable MP3 player. The MP3 players (Appendix A) were picked from the offering that is currently available in the market, and were chosen to be as broad a range as possible. The range of MP3 players was verified during a pilot study, which showed that there was a good spread in the data. The whole of the session was recorded using a voice recorder for later analysis.

The MSP looks at the participants' own relative judgments and concepts in order to investigate their individual perceptions and how they conceptualise beauty in objects. The MSP was run in three modes; free-sort, semi-structured sort and structured sort.

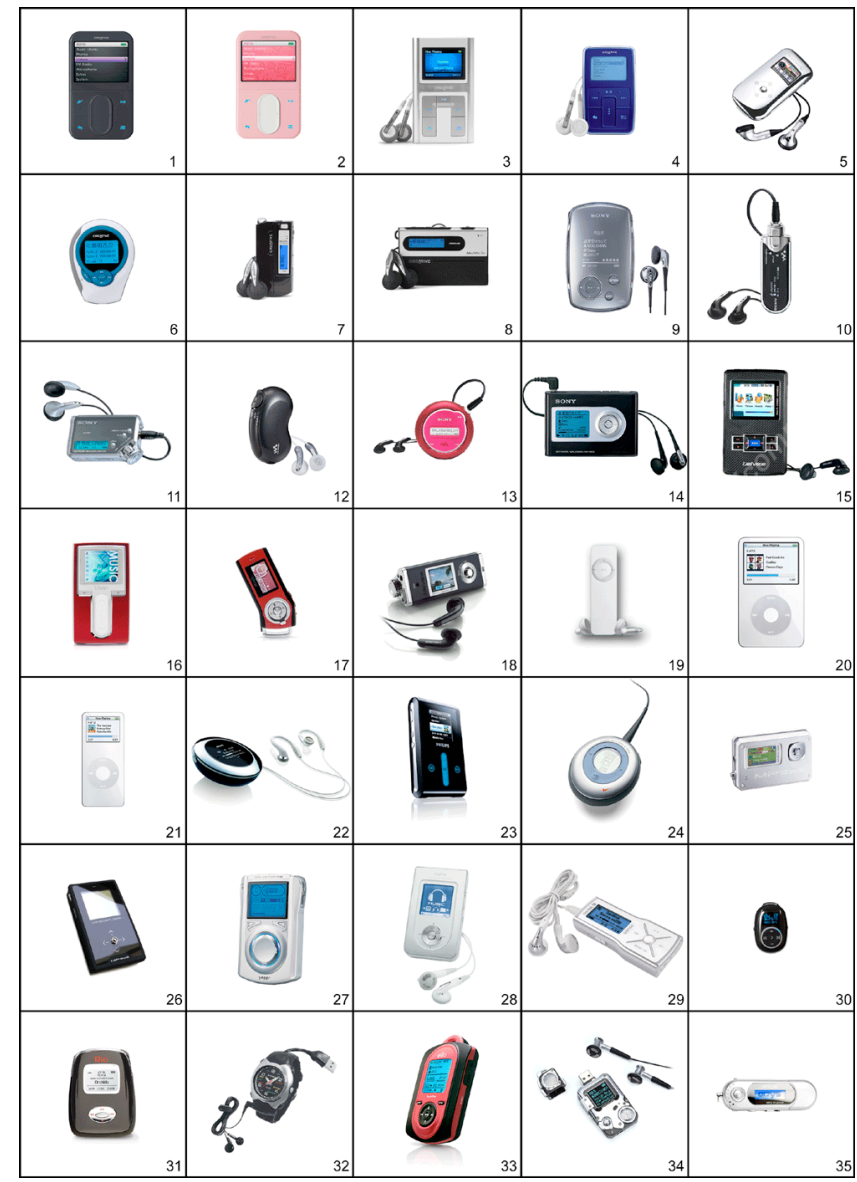

Figure 1 - MP3 players used in this study.

In the free-sort mode, the participants were asked to sort the cards for any criteria (constructs), into any number of piles and with any number of cards into each pile. The participants then attributed labels (categories) to each pile and explained their rationale. 
In the semi-structured mode, the participants were given the sorting criteria (in this case "Kinds of Beauty"), and then they were asked to sort the cards into any number of piles with any number of cards into each pile.

In the structured sort, the participants were given the sorting criteria, in this case "preference", and the number of piles and the meaning for each pile (in this case it was a 7-point preference scale). However, there were no restrictions on the number of cards per pile.

\section{RESULTS}

\section{Sorting Constructs}

The Multiple Sorting Procedure (MSP) was used for this part of the data collection. The participants were given the cards with the instruction to sort them into any number of piles for any reasons or criteria they wanted (free-sort). All participants were given the following verbal instruction (based on that given by Canter et al. (1985)):

\begin{abstract}
"I am carrying out a study on how users experience technology. So I am asking a number of people to look at the photographs of MP3 players (the photographs are 1:1 scale) and to sort them into groups in such a way that all the MP3 players in each group are similar to each other in some important way and different from those in the other groups. You can have as many groups as you like, and have as many MP3 players in each group as you like. It is your views that count. When you have carried out the sorting I would like you to tell me the reasons for your sorting, and what the MP3 players in each group have in common. Assume that they all have similar specifications."
\end{abstract}

Once sorted, the item codes were recorded from each photograph for each group. The participants were then asked to clarify the criterion (construct) of the sort, and to give a description for each of the groups within this criterion. On the more subjective sorts, such as "easy to use", the participants were asked to elaborate on the choices made. Open questions were used such as "what about these items make them easy to use?" Participants performed as many free sorts as they felt able to find new sorting criteria.

In order to have a systematic way of collating the constructs into structured data that can be analysed, a set of rules were devised. For a construct such as "controls" the rules will be the following:

1- Count all references to "controls".
2- If a participant used "controls", as a sorting criteria, then the count for references to "controls" is incremented by one.

3- If a participant sorted for "controls" and "size" at the same time, for example the participant may say "this pile is big with small controls, and this pile is small with round controls", then the count for references to "controls" is incremented by one, and the count for references to "size" is incremented by one.

4- Once all the references are counted, for all the participants, they are aggregated into a more concise data set. For example, if there was one count for "shape of controls" and one count for "number of controls", then they are aggregated under two counts for "controls".

In summary, the counting was done for any time a participant referenced that particular construct (as a sorting criteria) as a way of distinguishing between MP3 players.

All the sorts from the free-sort part of the data collection were analysed to assess the "constructs" that the participants had during the visual interaction. This data (Table-1) show a mixture of objective and subjective constructs.

The "cross-linking" construct refers to situations where the participant may have described the sorting criteria (the construct) in one way, and the individual categories within the construct, were described in another way. For example, participant A-02 used the construct "Sport" and the criteria within the sort were; light and heavy. Another example was "average comfortable-to-hold size", by participant A-06. Another example was with participant A-02, where he distinguished a sort on "shape \& display" and also said that a large display meant better quality. Also, participant A-14 used the construct of "size" and linked it to "user friendly". This suggests that size is related to usability somehow.

There were some constructs that seem to be concerned with functionality or specifications, but actually were more concerned with convenience. For example the "battery" construct was explained by participant A-60 as "MP3 players that show battery life".

Several participants saw item-32 as "just a watch" or "the watch", and even put it in a pile on its own, while others were happy to see it as an MP3 player. 


\begin{tabular}{|c|l|c|}
\hline No. & Construct & References \\
\hline 1 & Screen & 44 \\
\hline 2 & Size & 29 \\
\hline 3 & Controls & 25 \\
\hline 4 & Shape & 24 \\
\hline 5 & Colour & 22 \\
\hline 6 & Aesthetics & 18 \\
\hline 7 & Brand & 17 \\
\hline 8 & Design & 17 \\
\hline 9 & Functions & 17 \\
\hline 10 & Usability & 14 \\
\hline 11 & Convenience & 11 \\
\hline 12 & Buy & 11 \\
\hline 13 & Price & 8 \\
\hline 14 & Watch & 8 \\
\hline 15 & Headphones & 6 \\
\hline 16 & Cross-Linking & 6 \\
\hline 17 & iPod & 6 \\
\hline 18 & Orientation & 5 \\
\hline 19 & Construction Quality & 5 \\
\hline 20 & Sport & 4 \\
\hline 21 & Age & 4 \\
\hline 22 & Gender & 3 \\
\hline 23 & Weight & 1 \\
\hline 24 & Texture & 1 \\
\hline 25 & Battery & 17 \\
\hline & C & \\
\hline
\end{tabular}

Table $1-$ Constructs used in all the free-sorts by all participants.

The free-sort data were analysed using Multidimensional Scalogram Analysis (MSA) (Zvulun 1978, Wilson 1995). The MSA program provides a plot of all the MP3 players as points in geometric space, such that the more frequently two items are placed in the same category the closer together they are in the plot. Therefore, irrespective of the overt reason that the participant chose for placing the item in that category, it would be reasonable to assume that there is a physically visible property that helped the participants concur, knowingly or otherwise.

Even though the instructions were clear regarding the functional specifications (to ignore them), many participants still involved the specifications in the sorting task. Participant A-06 actually said that it would "not make sense" to sort them without including what he could assume, or remember about the functional specifications of the items he was seeing. What was also interesting about this particular session with A-06 is that he insisted that he was making logical judgements about the specifications throughout most of the session, and he chose item number 17 as his favourite, with reasons such as "well designed", "good size" and "solid state" [referring to the technology type]. However, when asked; "would you still like it if it was green?" the answer was an instant "No!". Participant A-02 also had reservation about not including specifications into his sorts, and in fact did included specifications and function on several occasions.

There were also participants who were not interested in any specifications and said that they would only wanted to know "how many songs can it hold" and "as long as it looks good".

The MSA plots were divided into regions and were given labels that are an interpretation by the researcher. The interpretations were derived from the aggregate of the constructs that the participants gave for the individual items, which consequently appear in the regions.

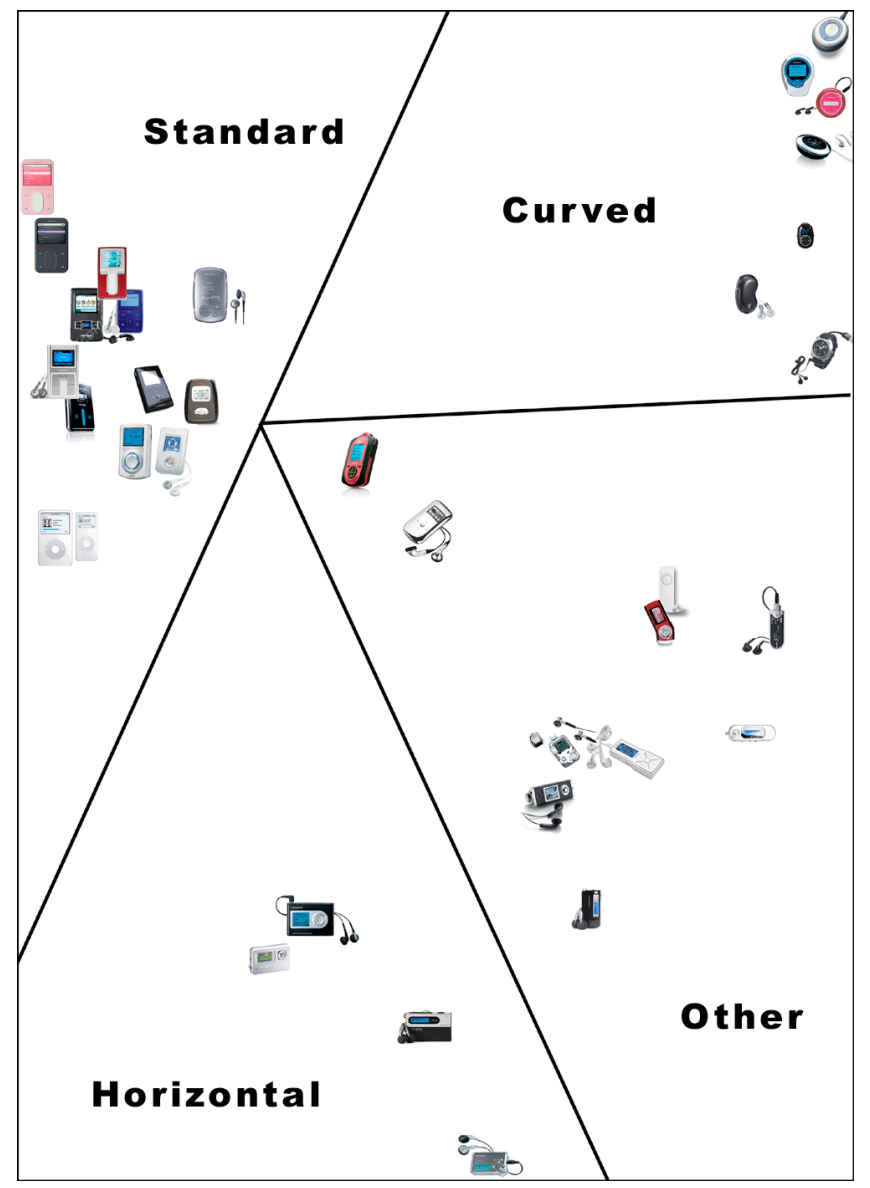

Figure 2-MSA of first sort for all participants.

The MSA (Figure-2) shows the data obtained in the first sort (of the free-sorts) of all participants. These data reflect the first impressions experienced by the participants. Although there are four regions, they can be grouped into two groups; simple (standard and horizontal) and non-simple (curved and other) designs. 


\section{Kinds of Beauty}

This part of the data was used to gain better insight into how the participants think about beauty, and to find out about what aspects of the MP3 player reflect the sense of beauty. The participants were asked to perform a MSP in a semi-structured sorting mode. The participants were asked to sort the cards into any number of piles for the criterion of "Kinds or types of Beauty". All participants were given the following verbal instruction:

\section{"Please sort the photographs for the criteria of Beauty into any number of groups. Sort them in such a way to show how they differ in 'Kinds of Beauty' or 'Types of Beauty'."}

At the end of the sort, the items' codes were recorded. Once the sorting was done, the participants were asked to explain the rationale and meanings behind their choices and an unstructured discussion was allowed to take place.

The "Kinds of Beauty" sort showed a very large range of ways of describing beauty categories and attributes. This data also showed common beauty categories along with idiosyncratic ones that only appear once amongst all the participants.

Although most participants were able to perform this sorting task easily and responding with such comments as "sure, I see what you mean" or getting straight into the task, a few did see it as a matter of scale, and would sort the photographs in a scalar manner; least beautiful (or ugly), to most beautiful.

Participant A-08 chose "the watch" (player number 32) as his favourite, and remarked that it was very "James Bond" and was visibly excited about the possibility of using it. I met this participant the very next day, and he said that he spent the night hunting on the World Wide Web for a place to buy the watch, and was interested to know if I would recommend any stores. During his "Kinds of Beauty" sort, this participant categorised this MP3 player as having "technological beauty". There was no correlation between preference and the beauty category chosen by the participant.

Participant A-51 pointed out an interesting "Kind of Beauty". When she sorted for "Kinds of Beauty", she used the following categories:
Average

Smooth rounded

Colourful

Ugly

Holiday

The category of "Holiday" was attributed to one MP3 player only, number 18 . When asked about what that meant, she said that the picture depicted on the screen of the player screen [showing a holiday scene] made her like the player, and it reminds her of a nice holiday. She subsequently gave the player the highest preference score of 7 .

\begin{tabular}{|c|l|c|}
\hline No. & Category & Ref. \\
\hline 1 & Beautiful & 8 \\
\hline 2 & Colour & 7 \\
\hline 3 & Ugly & 6 \\
\hline 4 & Average & 5 \\
\hline 5 & Nice & 5 \\
\hline 6 & Shape & 5 \\
\hline 7 & Attractive & 4 \\
\hline 8 & Functional & 4 \\
\hline 9 & Simple & 4 \\
\hline 10 & Sleek & 4 \\
\hline 11 & Bulky & 3 \\
\hline 12 & Gender & 3 \\
\hline 13 & Original & 3 \\
\hline 14 & Size & 3 \\
\hline 15 & Technological & 3 \\
\hline 16 & Boring & 2 \\
\hline 17 & Design & 2 \\
\hline 18 & Different & 2 \\
\hline 19 & Effort & 2 \\
\hline 20 & Futuristic & 2 \\
\hline 21 & Misc. & 2 \\
\hline 22 & Practical & 2 \\
\hline 23 & Quirky & 2 \\
\hline 24 & Smooth & 2 \\
\hline 25 & Stylish & 2 \\
\hline 26 & Texture & 2 \\
\hline 27 & Aesthetic & 1 \\
\hline 28 & Angular & 1 \\
\hline 29 & Classic & 1 \\
\hline 30 & Clutter & 1 \\
\hline 126 & 2 & \\
\hline
\end{tabular}

\begin{tabular}{|c|l|c|}
\hline No. & Category & Ref. \\
\hline 31 & Compact & 1 \\
\hline 32 & Complicated & 1 \\
\hline 33 & Conventional & 1 \\
\hline 34 & Cost & 1 \\
\hline 35 & Cute & 1 \\
\hline 36 & Dinky & 1 \\
\hline 37 & Dull & 1 \\
\hline 38 & Elegant & 1 \\
\hline 39 & Eye-catching & 1 \\
\hline 40 & Fiddly & 1 \\
\hline 41 & Form & 1 \\
\hline 42 & Geek & 1 \\
\hline 43 & Like & 1 \\
\hline 44 & OK & 1 \\
\hline 45 & Pleasing & 1 \\
\hline 46 & Regular & 1 \\
\hline 47 & Shiny & 1 \\
\hline 48 & Sport & 1 \\
\hline 49 & Stereotype & 1 \\
\hline 50 & Symmetry & 1 \\
\hline 51 & Streamlined & 1 \\
\hline 52 & Striking & 1 \\
\hline 53 & Tacky & 1 \\
\hline 54 & The Mark & 1 \\
\hline 55 & Traditional & 1 \\
\hline 56 & Trendy & 1 \\
\hline 57 & Unknown & 1 \\
\hline 58 & Unusual & 1 \\
\hline 59 & Weight & 1 \\
\hline & TOTAL & 122 \\
\hline & a & \\
\hline
\end{tabular}

Table 2 - This table shows the categories used in the "Kinds of Beauty" sorts by all participants, and the number of times they are referenced. (Ref. = References).

The MSA shown in Figure-3 shows four main regions that show different "Kinds of Beauty". This is consistent with the general discussions with the participants where there were regular references to "curved" and "shapely" shapes, and also "very standard", "average", "stereotypical" and "MP3 player look". The items in the "functional" group were also given names such as "tough", "dull", "male" and "old". 


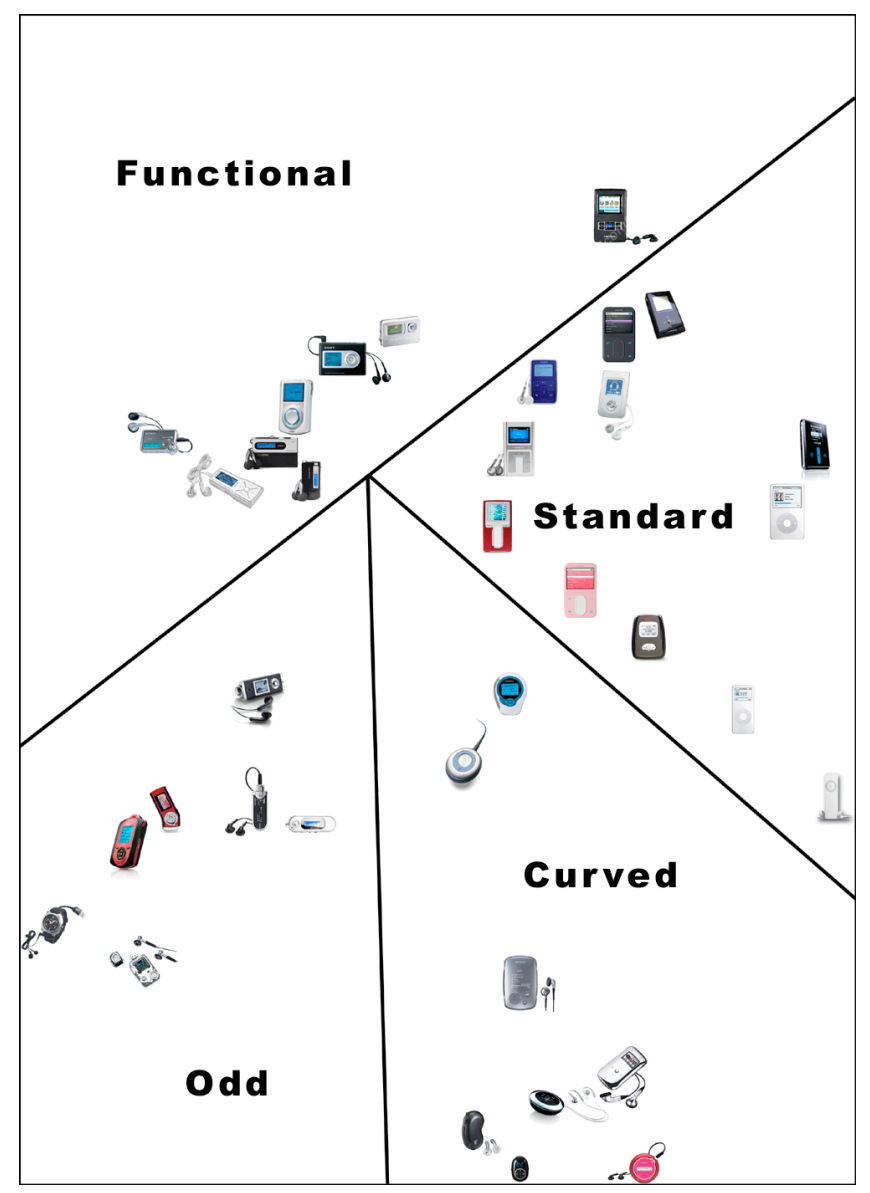

Figure 3 - MSA of "Kinds of Beauty" sort for all participants.

As with the MSA for the first-sort (Figure-2), the MSA for the "Kinds of Beauty" sort (Figure-3) could be grouped into two main groups; simple (functional and standard), and non-simple (odd and curved). This would suggest a similarity between "beauty" and the first-impression that users have when sorting photographs of MP3 players.

\section{Preference Sort}

The participants were finally asked to sort the cards according to "Preference". All participants were given the following verbal instruction:

"Please sort the photographs for personal Preference. Sort them into 7 groups, where "7" is the most preferred, and " 1 " is the least preferred."

Just before the participants were allowed to sort the photographs, seven numbered cards (with the numbers 1 to 7 printed on them) were spread evenly across the sorting surface. The intention was to provide a visual cue for the participants and ensure they followed the instructions correctly. Once the sorting was completed, the items' codes were recorded for each pile. The participants were asked to explain the rationale behind their choices and an unstructured discussion was allowed to take place.

A mean preference was calculated for each MP3 player and the data is shown in Figure-4.

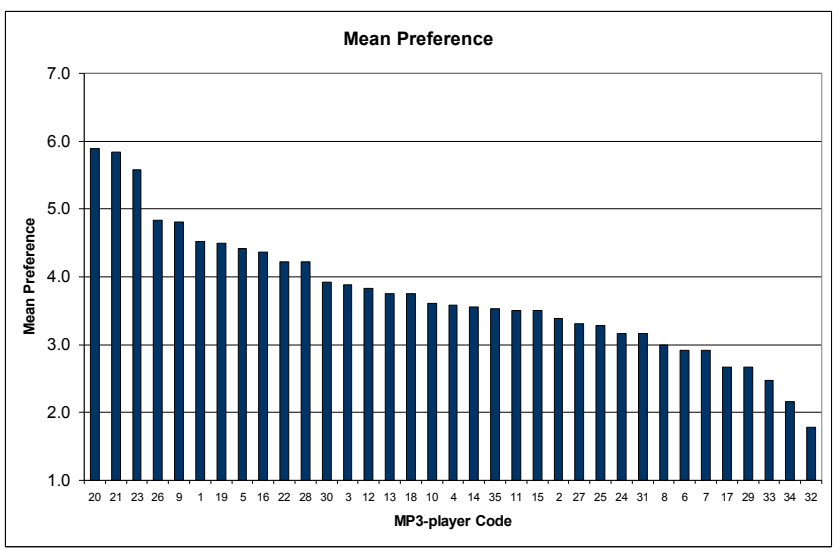

Figure 4 - Chart showing the mean preference for each item (averaged for all 36 participants).

The preference data were analysed using Smallest Space Analysis (SSA). SSA is a nonmetric MDS (Multidimensional Scaling) technique that represents variables as points in geometric space. The distance between the points is inversely proportional to the rank order of the associations between the variable. This means that the closer the points the more associated the variables they represent.

The structured preference sorting tasks allow insight on how the structure of physical properties underlying preference. As can be seen in 2D-SSA plot (Figure 6 $\& 7)$, there is a colour gradient across the plot, and there is also a screen colour variation (blue/dark screen at the bottom, and lighter/colourful screen at the top). There is also an orientation variation (landscape vs. portrait) and also a curved/small band that skirts the outside of the plot on the right. The meaning of the plot is that participants who preferred a particular item, are also likely to prefer another item closest to it, and unlikely to prefer an item far away from it, especially if it is on the opposite side of the plot. 


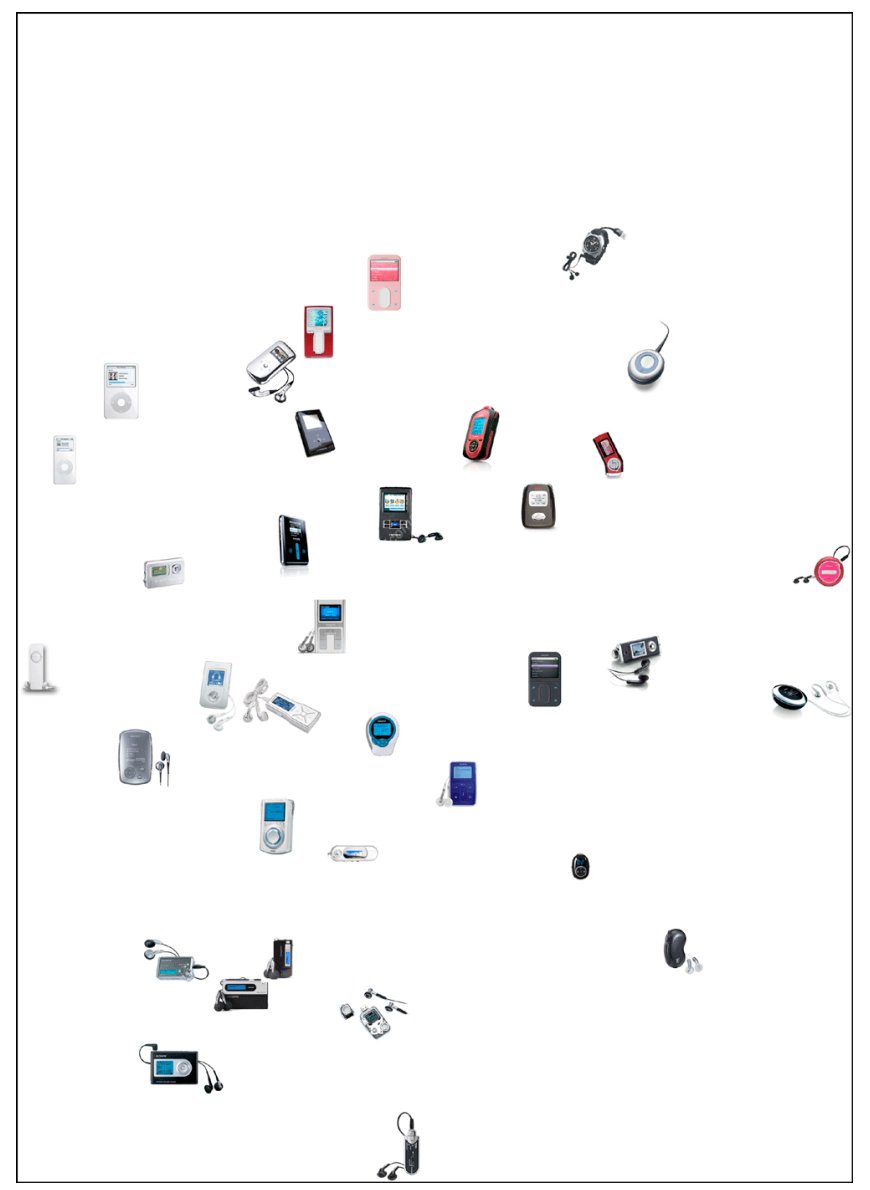

Figure 5 - 2D-SSA of preference sort for all participants (Guttman-Lingoes' coefficient of alienation $=0.345$ in 13 iterations).

The Guttman-Lingoes' coefficient of alienation for the 2D-SSA plot (Figure-5) was 0.345. Shye (Shye 1994, pp125) discusses the value of using this coefficient, and shows that it is best used as a discretionary guide, and ultimately the data is useful if trends are visible and interpretable, which they are in this data set.

There were several examples of the participants making gestures with their hands as they were viewing the photographs, as though they were testing something. When asked to elaborate on this behaviour, they would say that they were "trying it out". Participant A-06 also went on to say "I am trying to see if I can control the buttons in the right way". Conversely, participant A-09 said that he "could not imagine having it [item 32] on my wrist", while gesturing on his wrist. He said "I am intrigued, I tried to imagine having it on my wrist". When asked "you tried to imagine it?" he said "yes, I have tried, and I just can't!" Participant A-05 was gesturing with his hands as he saw one of the photographs, and when asked about his actions, he said that he "was trying it out".

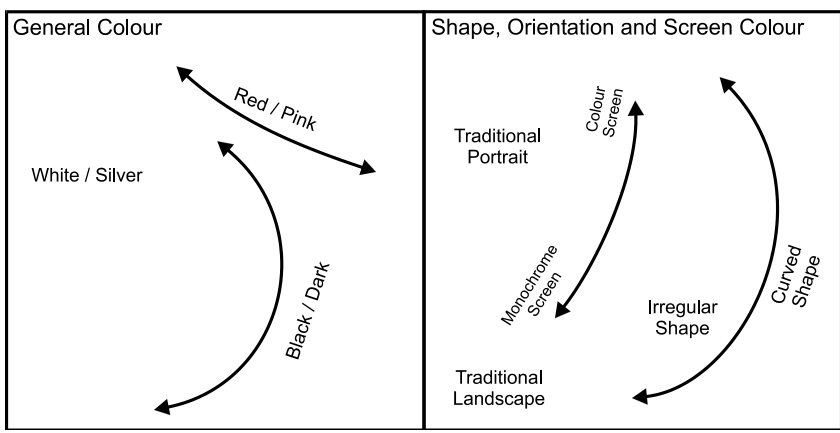

Figure 6 - Schematic diagram of SSA of preference showing general MP3 player colour distribution, shape, orientation and screen colour.

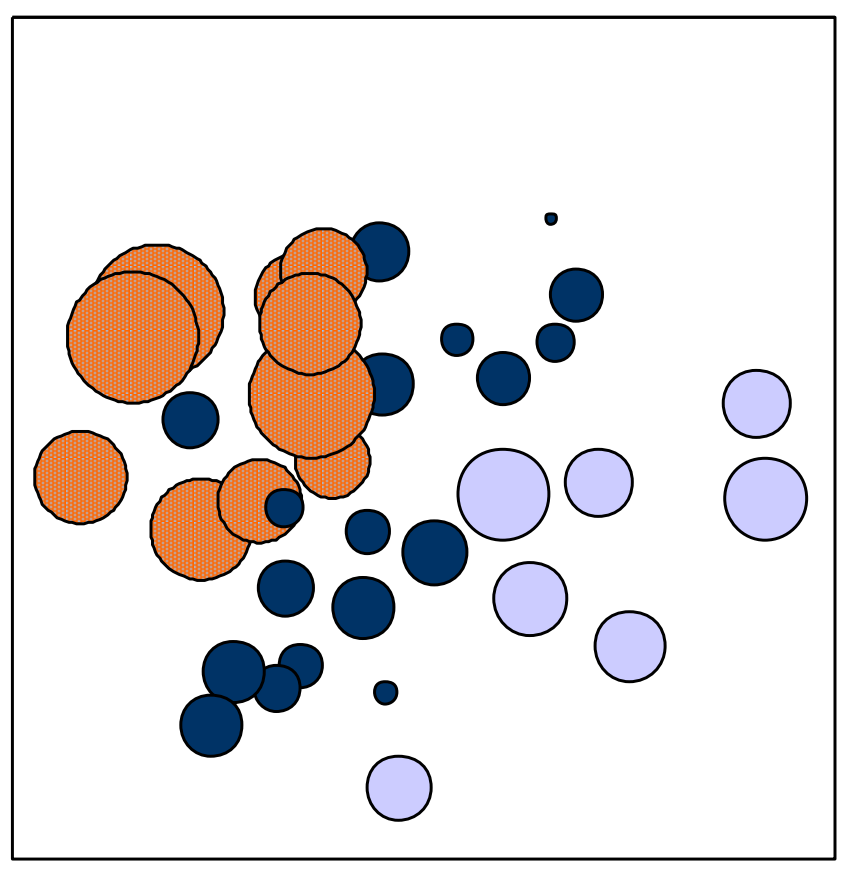

Figure 7 - 2D-SSA of preference sort for all participants showing mean preference. The size of the circle is directly proportional to the mean preference for each MP3 player. The positions of the items match the positions shown in Figure-5. The solid dark-blue circles form a band across the middle of the plot. These circles represent MP3 players that have a mean preference in the lower half (18 out of 35 items) of the population, i.e. they represent the half that has the least preference.

Participant A-14, referring to the time when he was shopping for his own MP3 player, said "it spoke to me [item 31]...you think about using it, about situations 
where you would use it...I fly to America...I thought about taking it out on the plane...people might be curious [watching me]...I could see myself using it...I can see it fitting my life...I literally positioned myself using it [on the plane]". This demonstrates a strategy that some participants use in order to verify a "fit", and ultimately influences their decision on preference.

The results of the SSA of preference ratings demonstrate that there appear to be two groups of MP3 players that are preferred by this group of participants. According to the principles of SSA, it is likely that those who prefer the players to the top left of the SSA plot (Figure $5 \& 7$ ) will have rated as less preferred the group of MP3 players toward the bottom right of the plot and vice versa. References to the actual players represented in these groups shows that the first group are primarily rectangular and do not tend to use colours beyond black, white and sliver. In contrast, the other group are primarily curved and unusual shapes that use fun imagery and some colour. Interestingly, this corresponds to the distinction between Modernism and Post-Modernism found to underlie architectural preference in Wilson's (1996) study.

\section{DISCUSSION}

This group of data collection methods, as a whole, include several opportunities for discovering salient aspects of the experience with MP3 players, such as past experiences that influence the current experience, as well as environmental and social factors that precede the specific interaction with the technology items. A key part of this approach is that the criteria that were elicited during the MSP provided a "tailored" framework for the discussion of the aesthetic constructs that were relevant to the participant and therefore allowed the participant to be fully engaged and able to reveal more of their salient experiences.

This study concentrated on the visual interaction with MP3 players, and participants were not given the opportunity to handle the devices. This could be seen as missing a vital component of interaction. However, we argue that this level of interaction is important in its own right, and the fact that the participant were engaged and were able to relate to the products, shows this validity. Essentially, this interaction is similar to the interaction via any visual medium such as paper or on-line catalogues or window shopping.
When the participants sorted the photographs, they could only see the objective aspects, and were overlaying their own interpretations and meanings on what they saw. The results of the free-sort MSA (Figure-2) showed that there are distinct objective parameters that were perceived by the participants, such as "rectangular" (portrait and landscape orientations), "curved" and "irregular" shapes. The constructs described in Table-1 show a richer range than the MSA, which shows that the simple, userdefined and objective, constructs such as colour, shape and size, are ultimately translated to constructs that are more personal and subjective such as "attractiveness", "beauty" and "easy-of-use" and they help create the initial impression made by the object. It is ultimately the relationship between the participant and the objective constructs that create the more subjective ones, and therefore concepts such as beauty lie within these relationships.

Participants also tended to link personal values to objective attributes such as "clean", "easy to use", "well designed", "simple" and "fun". An example of how an experiential response can be triggered by an objective aspect of an MP3 player, was the example of the "holiday" construct, that was triggered by the screen showing a holiday scene and ultimately lead to a high preference rating. The data also showed definitions of beauty ranging from "symmetry", "sleek" and "simple" to "trendy", "striking" and "eyecatching". Beauty was also defined as "technological", "futuristic" and "classic". These definitions are anchored to objective parameters, as seen in the groups in the MSA plots.

The regions shown in Figures $2 \& 3$, show a consistent grouping of the individual MP3 players, and both figures show an almost identical split between simple designs and non-simple designs. This is echoed in the preference plots (Figures 5 \& 7) where there seems to be two distinct groups of preferences; modern and post-modern.

Although the data show that there is a degree of consensus (Figure-4) of preferences of the MP3 players, it is also clear that there are individual variations. It is therefore difficult to conclude a simple relationship between individual preference and meanpreferences, for example, item Number 32, which is a watch that is also an MP3 player. Most participants hated it, and said so unreservedly, while two participants were totally enamoured by the item, to the extent that one of them subsequently searched the Internet to find the watch in order to buy it. 
CoDesign - Intetrnational Journal of CoCreation and design and the Arts, Vol 3 (51): 59-74, 2007.

Table-2 shows the distribution of construct counts for "Kinds of Beauty". Power distributions occur naturally and they are given different names in different disciplines e.g. Zipf and Pareto distributions (Zipf 1949). This phenomenon is also referred to as "The Long Tail". There are also many theories on why this is a general phenomenon in nature (Newman 2000), and the question of "why this happens specifically in beauty", could be a research project in its own right. The large number of beauty categories shows a large variety of different ways of defining beauty, although there are a few categories that are most popular. However, the smaller number of objective constructs shows a limited number of perceived objective parameters.

A few non-owners have owned an MP3 player in the past, or their partner has one, they sometimes use. This makes the category of "owner" ambiguous in its meaning. We also saw several examples where there was a link between the preferred MP3 and the "exposure" the participant had to that particular device, in the physical sense as well as the advertising media sense. This is consistent with the mereexposure effect (Zajonc 1980), and participants readily admitted that they know about it, and their friends have it, therefore they prefer it.

The notion of preference has only had little exposure in the general debate where the "halo effect" was cited as a major factor (De Angeli \& Sutcliffe 2006), where users are likely to have enhanced usability and preference towards devices that are attractive.

Preference seems to be influenced by "trials". Some participants were "trying out" the MP3 players to see how they could be used, how they would fit into their lives and the way they would go about using them in different scenarios. These scenarios included social occasions as well as usability and convenience situations.

Although participants were explicitly asked to ignore technical specifications, most of them found it very difficult to separate beauty and preference from specifications. This could be linked with the crosslinking that was apparent in many discussions and sorting criteria, were objective attributes were given meanings that were subjective in nature.

Frohlich (2004) discussed consistencies within groups that agree about examples of beauty, and he also discussed individual idiosyncratic examples. Our data concurs with this view. However, we also show that beauty can also be a "Kind" of beauty, and these kinds are borne of the way participants relate to the items under investigation. So, we conclude that beauty is not a scalar quantity along some arbitrary dimension, and neither a singular emotional response, but a result of complex relationships between the object itself and how an individual relates to it. Of course, it is important to note that such relationships could well be socially constructed (Bull 2005). For example, the attraction towards the iPod is not just about the device and its physical attributes, but also about membership of the iPod community.

The MSP data collection method, along with the MSA technique, has provided a useful insight into the users' conceptualisations of their interaction with MP3 players, and this methodology could be extended to other artefacts and contexts of interaction. Overall, these data show that the Facet Theory approach provides a useful set of techniques that can help us further understand beauty within technological artefacts.

\section{CONCLUSION}

We believe that beauty is a function of the relationships between many components, tangible and intangible. We also believe that beauty is linked to a sense of wonderment and surprise, and the intensity of beauty, as a response, begins to wane when expectations and promises are not met, and therefore can be fragile. However, there was evidence that beauty in MP3 players follows that of buildings, as demonstrated by Wilson (1996) who showed a basic split; Modern and Post-Modern. There was no evidence of a direct relationship between preference and beauty, and we saw examples where preferences can shift in an instant and are linked to mundane factors such as specifications, convenience and cost. Participants also seemed to make holistic judgements about the fit of the individual products to their lifestyle and image. Further investigation into the notion of preference is required along with studies that explore how physical interactions influence beauty and preference. Work is also required in correlating these finding with individual differences between users, in order to obtain a usable model or guidelines that can be used by designers who wish to provide more pleasurable products for users. 


\section{APPENDICES}

\section{Appendix - A: MP3 Players used in the study}

\begin{tabular}{|c|c|c|}
\hline Code & Brand & Model \\
\hline 1 & Creative & Zen Vision \\
\hline 2 & Creative & Zen Vision \\
\hline 3 & Creative & Zen Sleek \\
\hline 4 & Creative & Zen Micro \\
\hline 5 & Maxfield & Diamond \\
\hline 6 & Creative & MuVo Sport C100 \\
\hline 7 & Creative & MuVo TX \\
\hline 8 & Creative & MuVo Slim \\
\hline 9 & Sony & NW-A3000 \\
\hline 10 & Sony & NW-E407 \\
\hline 11 & Sony & NW-E95 \\
\hline 12 & Sony & NW-E205 \\
\hline 13 & Sony & NW-E107 \\
\hline 14 & Sony & NW-HD3 \\
\hline 15 & iRiver & $\mathrm{H} 340$ \\
\hline 16 & iRiver & $\mathrm{H} 10$ \\
\hline 17 & iRiver & T10 \\
\hline 18 & iRiver & iFP-1090 \\
\hline 19 & Apple & iPod Shuffle \\
\hline 20 & Apple & iPod \\
\hline 21 & Apple & iPod Nano \\
\hline 22 & Philips & PSA610 \\
\hline 23 & Philips & HDD1620 \\
\hline 24 & Nike + Philips & PSA 220 \\
\hline 25 & MPeye & HTS-200 \\
\hline 26 & MPeye & HTS-170 \\
\hline 27 & Yepp & YP-900 \\
\hline 28 & Sanyo & HDP-M3000 \\
\hline 29 & SanDisk & Sansa M250 \\
\hline 30 & Pebble & Pebble \\
\hline 31 & Rio & Carbon CE2100 \\
\hline 32 & Xonix & MP-001 \\
\hline 33 & Elio & M310 \\
\hline 34 & DNT & Star 5-IR \\
\hline 35 & Odys & MP3-S2 \\
\hline
\end{tabular}

\section{REFERENCES}

1. Blythe, M.A., Overbeeke, K., Monk, A.F. and Wright, P.C., Funology: from usability to enjoyment, 2003 (Kluwer Academic Publishers: Dordrecht, Boston, London).

2. Bull M., No Dead Air! The iPod and the Culture of Mobile Listening. Leisure Studies, 2005 Vol. 24, No. 4. pp. 343-355.

3. Canter, D. (Ed.), Facet Theory: Approaches to Social Research, 1985 (Springer Verlag: New York).

4. Canter D., Brown J. \& Groat L., A Multiple Sorting Procedure. In Brenner, M., Brown J. \& Canter D. (Eds), The Research Interview: Uses and Approaches, 1985 (Academic Press: London).

5. Card, S., Moran, T., \& Newell, A., The psychology of human-computer interaction. 1983 (Lawrence Erlbaum Associates: Hillsdale, NJ).
6. De Angeli A., Sutcliffe A., \& Hartmann J., Interaction, usability and aesthetics: what influences users' preferences? Proceedings of the 6th ACM conference on Designing Interactive systems, pp. 271-280, 2006 (ACM Press: NY, USA).

7. Frohlich D.M., Beauty as a design prize, 2004 HumanComputer Interaction. Volume 19, pp. 359-366.

8. Hassenzahl M., The Interplay of Beauty, Goodness, and Usability in Interactive Products, 2004 HumanComputer Interactions. Volume 19, pp. 319-349.

9. Jordan P., Designing Pleasurable Products. 2000 (Taylor \& Francis: London).

10. McCarthy J. and Wright P., Technology as Experience. 2004 (MIT Press: Cambridge, MA, USA).

11. Newman M., The power of design, 2000 Nature 405, 412-413.

12. Norman D. Emotional design: Why we love (or hate) everyday things, 2003 (New York: Basic Books).

13. Norman D., Introduction to This Special Section on Beauty, Goodness, and Usability, 2004 HumanComputer Interactions. Volume 19, pp. 311-318.

14. Osgood C. E., Suci G J \& Tannenbaum P. H., The Measurement of Meaning, 1957 (Illinois University Press: Urbana, IL).

15. Shye, S., Elizur, D. \& Hoffman, M., Introduction to facet theory, 1994 (Sage: Thousand Oaks).

16. Tractinsky, N., Shoval-Katz, A., Ikar, D., What is beautiful is usable, 2000 Interacting with Computers 13, 127-145.

17. Wilson M. A. and Canter D., The Development of Central Concepts during Professional Education: An Example of a Multivariate Model of the Concept of Architectural style, 1990 Applied Psychology: An International Review. Volume 39 (4), pp. 431-455.

18. Wilson M., Structuring Qualitative Data: multidimensional scalogram analysis. In Breakwell G., Hammond S. \& Fife-Shaw C. (Eds), 1995 Research Methods in Psychology. (Sage Publications: London).

19. Wilson M., The Socialization of Architectural Preferences, 1996 Journal of Environmental Psychology, 16: 33-44.

20.Zajonc R., Feeling \& Thinking: Preferences Need No Inferences, 1980 American Psychologist 35: 151-75

21.Zipf, G. K., Human Behavior and the Principle of Least Effort, 1949 (Addison-Wesley: Reading).

22.Zvulun E., Multidimensional Scalogram Analysis: the method and its application. In Shye S. (Ed.), Theory Construction and Data Analysis in the Behavioural Science, 1978 (Jossey-Bass: San Francisco). 